\title{
ANÁLISE DA APLICAÇÃO DO MÉTODO AHP EM INDICADORES DE POTENCIALIDADE NA IMPLANTAÇÃO DE PARQUES EÓLICOS
}

\author{
ANALYSIS OF THE APPLICATION OF THE AHP METHOD IN POTENTIALITY INDICATORS IN \\ WIND FARM IMPLEMENTATION
}

\section{Natacha Sousa Javarini ${ }^{1 *}$, Vanielle Aparecida do Patrocinio Gomes ${ }^{2}$, \& Rodrigo Randow de Freitas ${ }^{3}$}

\author{
${ }^{1}$ Departamento de Matemática Aplicada (DMA) do Centro Universitário Norte do Espírito Santo da \\ Universidade Federal do Espírito Santo. ${ }^{23}$ Departamento de Engenharias e Tecnologia do Centro Universitário \\ Norte do Espírito Santo da Universidade Federal do Espírito Santo. \\ 1"natachajavarini@hotmail.com² vaniellea.gomes@hotmail.com ${ }^{3}$ rodrigo.r.freitas@ufes.br
}

\section{ARTIGO INFO.}

Recebido em: 01.12.2020

Aprovado em: 17.12.2020

Disponibilizado em: 08.02.2021

Palavras-Chave:

AHP; Energia Eólica; Pesquisa Operacional.

KEYWORDS:

AHP; Wind Energy; Operations Research.

*Autor Correspondente: Javarini, N. S.

\section{RESUMO}

Ao considerar o cenário energético mundial atual, a fonte eólica é uma das grandes promessas para o futuro. Logo, justifica-se o aprofundamento dos estudos sobre projetos eólicos e suas particularidades, por se tratar de uma fonte de carácter renovável e que provoca o menor impacto no ambiente. Este estudo tem como finalidade discutir sobre os indicadores que influenciam na instalação de um parque eólico, por meio de comparações paritárias, de acordo com o método de tomada de decisão multicritério. Para isso, utilizou-se o Método Analytic Hierarchy Process para hierarquizar os critérios e indicadores que influenciam em tal implantação. O AHP utiliza a matemática para processar as preferências de indivíduos ou grupos tomadores de decisões, sendo o método facilitador na resolução de problemas por meio de um algoritmo. Os resultados apontaram o indicador que ocupou o primeiro lugar no ranking de tomada de decisão, que foi o ambiental, este por sua vez teve é composto por critérios com maiores pesos nos critérios de acordo com teste realizado por meio matriz de julgamentos. Em especial o critério vento, que se destacou na opinião dos pesquisadores, como sendo aquele que exerce uma maior influência quando se pensa em implantação de parque eólico.

\begin{abstract}
When considering the current world energy scenario, a wind source is one of the great promises for the future. Therefore, further studies on wind projects and their particularities are justified, as it is a renewable source and has the least impact on the environment. This study has as its theme about the indicators that influence the installation of a wind farm, through peer comparisons, according to the multicriteria decisionmaking method. To do this, use the Analytic Hierarchy Process Method to rank the criteria and indicators that influence such implementation. The AHP uses mathematics to process as preferential, or decision-making groups, being the facilitating method in solving problems through an algorithm. The results indicated the indicator that occupied the first place in the ranking of decision making, which was the environmental one, which in turn had composed of criteria with greater weights in the criteria according to the test performed by the matrix of judgments. In particular, the wind criterion, which stands out in the opinion of the researchers, as being the one that exerts the greatest influence when considering wind farm implantation.
\end{abstract}



potencialidade na implantação de parques eólicos. Brazilian Journal of Production Engineering, 7(1), 17-30.

\section{INTRODUÇÃO}

A energia é a principal propulsora dos vários processos da produção humana e não se consegue ver outra realidade social que envolva trabalho e produção, que direta ou indiretamente não levem em consideração o uso da energia (Bechert et al., 2015).

Os avanços nas mais diversas formas de sua utilização da energia acompanharam ou foram impulsionadores do desenvolvimento da sociedade atual, já que a mesma sofisticou o seu consumo, por exemplo, com a criação de produtos que exigem cada vez mais fontes de energia. Com isso, prevê-se que a demanda mundial de eletricidade aumente $60 \%$ até 2030 , significando que a carga produzida e disponível atualmente não irá acompanhar a consumo acelerado da população. Uma possível solução? Garantir a sustentabilidade da energia, ou seja, equilibrar os objetivos energéticos econômicos, sociais e ecológicos (Hinrichs, \& Kleinbach, 2003).

Em busca desta segurança energética, os tomadores de decisão procuram, junto com a iniciativa privada, diversificar a matriz energética locail. Dentre as possíveis fontes de energia destacamse: petróleo, gás, carvão, álcool, recursos hídricos, lenha e fontes limpas e renováveis, como a energia solar, térmica e eólica (MME, 2007).

Ao considerar o cenário energético mundial atual, a fonte eólica é uma das grandes promessas para o futuro, visto que possui uma melhor qualidade ambiental e por sua abundância em várias partes do mundo. A energia que se produz a partir do vento pode trazer inúmeros benefícios para a sociedade, pois além da sua contribuição no processo de produção sustentável, contribui também para o processo de produção de energia no país (Nascimento et al., 2012; Gomes, \& Henkes, 2015; Silveira, 2017).

A energia eólica se transformou em uma peça fundamental na geração de energia, principalmente da energia elétrica, onde houve uma grande expansão na pesquisa e desenvolvimento (Pinto \& Santos Neto, 2012). Em relação ao Brasil, segundo Pereira Neto (2013), o incentivo à energia eólica remete a década de 90 e surge como uma tendência internacional, na tentativa de os governos garantirem segurança energética. Segundo informações fornecidas pela Abeeolica (2020), atualmente o Brasil conta com 619 usinas eólicas instaladas, o que soma 15,4 GW instalados.

Considerando que atualmente a sociedade almeja por formas de energias sustentáveis, e por uma outra ótica, uma economia forte, onde não se prejudique a qualidade de vida das próximas gerações, é justificável o aprofundamento dos estudos sobre projetos eólicos e suas particularidades, impulsionando a comunidade científica a pesquisar e desenvolver estratégias para o aproveitamento de fontes alternativas de energia. Fontes essas de carácter renovável e que provoquem o menor impacto ambiental, econômico e social possível.

Assim, o presente estudo tem como finalidade discutir sobre os indicadores que influenciam na instalação de um parque eólico, por meio de comparações paritárias, de acordo com o método de tomada de decisão multicritério. Dentre eles Gazzaneo (2008) destaca o Analytic Hierarchy Process (AHP), principalmente pela facilidade, estruturação e aplicação. 
Citação (APA): Javarini, N. S., Gomes, V. A. do P., \& Freitas, R. R. de (2021). Análise da aplicação do Método AHP em indicadores de potencialidade na implantação de parques eólicos. Brazilian Journal of Production Engineering, 7(1), 17-30.

\section{Método AHP (ANALYTIC Hierarchy PRocess)}

Dentre os métodos de tomada de decisão, tem-se o AHP, desenvolvido por Thomas Lorie Saaty na década de 70 (Saaty, 1980), para hierarquização de alternativas utilizando a comparação par a par, o método auxilia na escolha, priorização ou na avaliação e pode ser aplicado em conjunto com outras ferramentas (Ruy, \& De Paula, 2012).

Desenvolvido para se acomodar à natureza humana ao invés de forçar os decisores a seguirem uma linha de pensamento - o que viola o bom senso -, o AHP é um processo que permite a resolução de problemas políticos e sócio econômicos complexos (Saaty, 1990).

O AHP utiliza a matemática para processar as preferências de indivíduos ou grupos tomadores de decisões, sendo entendido como um método facilitador na resolução de problemas por meio de um algoritmo. O método já foi aplicado em áreas como solução de conflitos, política energética, influência de nações, gestão de sistemas de saúde, alocação de recursos, estratégia corporativa e em áreas de nível estratégico, tático e operacional (Colin, 2007).

Para Saaty (1990), o AHP procura tratar a complexidade de um problema decompondo-o em uma estrutura hierárquica, formando uma árvore invertida como mostra a Figura 1, onde no primeiro nível encontra-se o objetivo ou meta de decisão, passando por critérios e alternativas, em sucessivos níveis, fazendo com que esta última tenha uma ordem prioritária.

Figura 1. Estrutura hierárquica básica do AHP

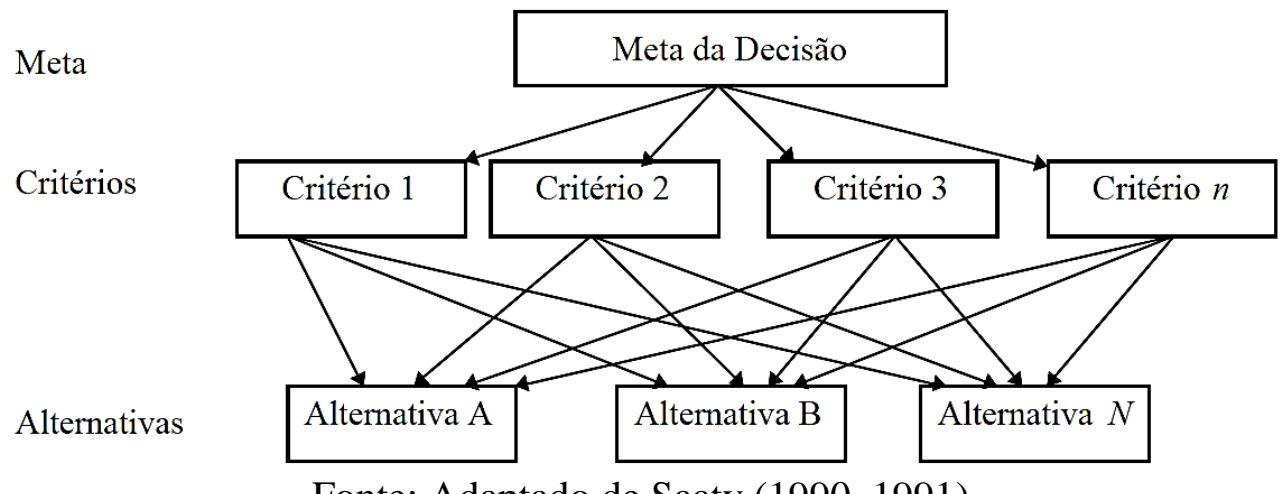

Fonte: Adaptado de Saaty (1990, 1991).

Assim, segundo este mesmo autor, deve-se definir o problema do estudo e a estrutura da hierarquia de decisão. Em seguida deve ser construída a matriz de julgamentos, que por sua vez, obedece a teoria da matriz Recíproca (Figura 2), em que n é o número de elementos dessa matriz, onde: $\mathrm{a}_{\mathrm{ij}}>0 \rightarrow$ positiva, $\mathrm{a}_{\mathrm{ij}}=1 \therefore \mathrm{a}_{\mathrm{ji}}=1$ e $\mathrm{a}_{\mathrm{ij}}=1 / \mathrm{a}_{\mathrm{ji}} \rightarrow$ recíproca (Gomes et al., 2016).

Conforme Saaty (1991), para cada julgamento registrado na linha i e coluna j, representado por aij, há um valor igual a 1/aji na posição recíproca, isto é, na posição de linha j e coluna i. Considerando as posições de elementos de linha e coluna i e j, respectivamente, variando de 1 a n, os elementos aij obedecem às seguintes regras:

Regra1: Se aij $=\alpha$, então aji $=1 / \alpha, \alpha \neq 0$, onde $\alpha$ é o valor numérico do julgamento baseado na escala de Saaty (1991). Logo, temos aji =1/aji.

Regra2: Se ai é julgado de igual importância relativa a aj, então aij = 1 e aji = 1; e, em particular, aij $=1, \forall \mathrm{i}=\mathrm{j}$. 
Citação (APA): Javarini, N. S., Gomes, V. A. do P., \& Freitas, R. R. de (2021). Análise da aplicação do Método AHP em indicadores de potencialidade na implantação de parques eólicos. Brazilian Journal of Production Engineering, 7(1), 17-30.

Figura 2. Matriz de julgamentos.

$$
A=\left[\begin{array}{cccc}
1 & a_{12} & \ldots & a_{1 n} \\
1 / a_{21} & 1 & \ldots & a_{2 n} \\
\vdots & \vdots & \ldots & \vdots \\
1 / a_{n 1} & 1 / a_{n 2} & \ldots & 1
\end{array}\right]
$$

Fonte: Gomes et al., (2016)

Esta matriz é enviada à pesquisadores da área para que de acordo com a Escala Fundamental de Saaty (Tabela 1), proposta pelo método AHP, façam seus julgamentos quanto a importância dos critérios que compõem a estrutura hierárquica, comparando-os par a par (Saaty, \& Vargas, 1979).

Tabela 1. Escala Fundamental de Saaty.

\begin{tabular}{ccc}
\hline $\begin{array}{c}\text { Intensidade da } \\
\text { Importância/Preferência }\end{array}$ & Definição & Explicação \\
\hline $\mathbf{1}$ & $\begin{array}{c}\text { Igualmente } \\
\text { importante/preferível }\end{array}$ & $\begin{array}{c}\text { Os dois fatores são igualmente } \\
\text { importantes/preferíveis }\end{array}$ \\
\hline $\mathbf{3}$ & $\begin{array}{c}\text { Importância/Preferência } \\
\text { moderada }\end{array}$ & $\begin{array}{c}\text { Importância/Preferência moderada } \\
\text { por um dos fatores }\end{array}$ \\
\hline $\mathbf{5}$ & Importância/Preferência forte & $\begin{array}{c}\text { Importância/Preferência forte por } \\
\text { um dos fatores }\end{array}$ \\
\hline $\mathbf{9}$ & Importância/Preferência muito \\
forte & $\begin{array}{c}\text { Importância/Preferência muito } \\
\text { forte por um dos fatores }\end{array}$ \\
\hline $\mathbf{2 , 4 , 6 ~ e ~ 8}$ & Importância/Preferência \\
absoluta & $\begin{array}{c}\text { Importância/Preferência } \\
\text { absolutamente maior por um dos } \\
\text { fatores }\end{array}$ \\
\hline
\end{tabular}

Fonte: Adaptado de Saaty (2000).

Para verificar a existência de desvio entre as comparações, como Berzins (2009) sugere, realizase o teste de inconsistência, onde é calculada a Razão de Consistência dos julgamentos (RC), obtida por meio da Equação (1):

$$
R C=\frac{I C}{I R}
$$

Onde IR é o Índice Randômico, padronizado e dependente da ordem n da matriz como mostra a Tabela 2, e IC é o Índice de Consistência, dado por IC $=(\lambda$ máx $-\mathrm{n}) /(\mathrm{n}-1)$, onde $\lambda$ máx é o maior autovalor da matriz de julgamentos. Para Saaty (2001), RC deve ser menor ou igual a 0,20 para que possa ser considerado aceitável.

Tabela 2. Índice Randômico

\begin{tabular}{c|c|c|c|c|c|c|c|c|c|c|c|c|c}
\hline $\mathbf{n}$ & $\mathbf{3}$ & $\mathbf{4}$ & $\mathbf{5}$ & $\mathbf{6}$ & $\mathbf{7}$ & $\mathbf{8}$ & $\mathbf{9}$ & $\mathbf{1 0}$ & $\mathbf{1 1}$ & $\mathbf{1 2}$ & $\mathbf{1 3}$ & $\mathbf{1 4}$ & $\mathbf{1 5}$ \\
\hline IR & 0,58 & 0,90 & 1,12 & 1,24 & 1,32 & 1,41 & 1,45 & 1,49 & 1,51 & 1,54 & 1,56 & 1,57 & 1,59 \\
\hline \multicolumn{10}{c}{ Onte: Saaty $(1991)$}
\end{tabular}

Para a realização do teste, as matrizes são submetidas ao cálculo do autovalor máximo, dado pela Equação (2), onde T é o somatório das colunas das matrizes e w é o autovetor normalizado.

$$
\lambda m a ́ x=T . w
$$

O autovetor dá a ordem de prioridade e o autovalor é a medida de consistência do julgamento.

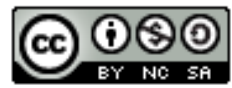



potencialidade na implantação de parques eólicos. Brazilian Journal of Production Engineering, 7(1), 17-30.

Logo, faz-se necessário para cada matriz de julgamento o cálculo do autovetor, que pode ser estimado pela média geométrica, apresentada na Equação (3), de cada linha das matrizes (Saaty, 2001), e a seguir deve-se realizar a normalização. Segundo Saaty (1991), o autovetor representa a importância relativa do elemento analisado para que o objetivo seja atingido.

$$
w_{i}=\sqrt[n]{\prod_{j=1}^{n} a_{i j}}
$$

Após concluir os testes de inconsistência, realiza-se a análise para estabelecer a ordem prioritária das alternativas, para assim responder ao objetivo inicial descrito no primeiro nível da estrutura hierárquica.

\section{Metodologia}

Testou-se nesse estudo o Método AHP, utilizado para integrar e analisar os dados coletados, um método de análise de multicritérios, que consiste em tomar decisões que envolvem complexidade e subjetividade (Saaty, 1988). Assim, foi definido o problema do estudo e estruturada a hierarquia de decisão a partir da revisão bibliográfica inicial. Com o intuito de se conseguir hierarquizar os indicadores relevantes na implantação de um parque eólico, o estudo abordou indicadores e critérios. Cada abordagem citada consiste em uma composição de seu nível subsequente, sendo assim, informações coletadas para os critérios deram suporte para a formação dos indicadores, que são as alternativas a serem priorizadas.

Com a estrutura hierárquica definida foi elaborada a matriz de comparação par a par, que foi enviada, em forma de questionário, aos pesquisadores (teste), tal matriz é composta pelos critérios identificados como importantes na implantação de parques eólicos, para que estes sejam julgados quanto à sua importância.

Com a matriz elaborada realizou-se o teste, que tem como característica o caráter experimental e é aplicado em uma amostra pequena de participantes (Muriuci et al., 2012). O teste é considerado fundamental para uma pesquisa, para que a população alvo tenha contato com as questões e possibilitando que o pesquisador se certifique que haja o entendimento e interpretação correta pelos indivíduos (Britol ,\& Magalhães, 2017).

Chaer et al., (2011) também recomendam a realização de um teste, que consiste na aplicação de 10 a 20 questionários de maneira que as respostas obtidas mostrem ao pesquisador se suas perguntas foram formuladas com sucesso.

Para encontrar as prioridades foi realizado o teste, com os julgamentos de pessoas determinadas por acessibilidade/proximidade com os autores e também com alguma experiência anterior com a metodologia AHP. Os questionários foram enviados via e-mail, e o público testado foi composto por 10 indivíduos, com idades entre 18 e 40 anos, de 6 municípios diferentes localizados no estado do Espírito Santo, com prazo máximo de 5 dias corridos a partir do recebimento do e-mail para o envio do questionário respondido. Este estudo será utilizado na aplicação efetiva do método, utilizando o julgamento de especialistas na área.

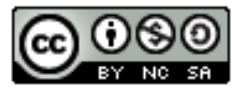


Citação (APA): Javarini, N. S., Gomes, V. A. do P., \& Freitas, R. R. de (2021). Análise da aplicação do Método AHP em indicadores de potencialidade na implantação de parques eólicos. Brazilian Journal of Production Engineering, 7(1), 17-30.

Nesta fase do teste os indivíduos selecionados responderam ao questionário utilizando a Escala Fundamental de Saaty, proposta pelo método AHP (Saaty, \& Vargas, 1979). A seguir foi realizado o teste de inconsistência de cada uma das matrizes, onde optou-se por descartar as respostas dos entrevistados que atingiram níveis superiores a $20 \%$ de inconsistência, como estabelece Saaty (1980). Todos os cálculos foram realizados com o auxílio do Microsoft Excel® 2016.

Assim, cada critério apresentou um peso relativo, encontrado por meio da normalização de seus autovetores, onde foram consideradas as médias das 10 matrizes respondidas. Porém, para os indicadores esses pesos foram considerados a soma dos pesos dos critérios que os compõem.

\section{RESUltados E Discussão}

A partir da revisão bibliográfica a respeito do tema, foi elaborada a estrutura hierárquica proposta pelo método AHP, sendo que no nível 1 encontra-se o objetivo geral, no nível 2 estão os critérios e no nível 3 estão as alternativas, que são os indicadores (Figura 3).

Figura 3. Estrutura hierárquica de decisão

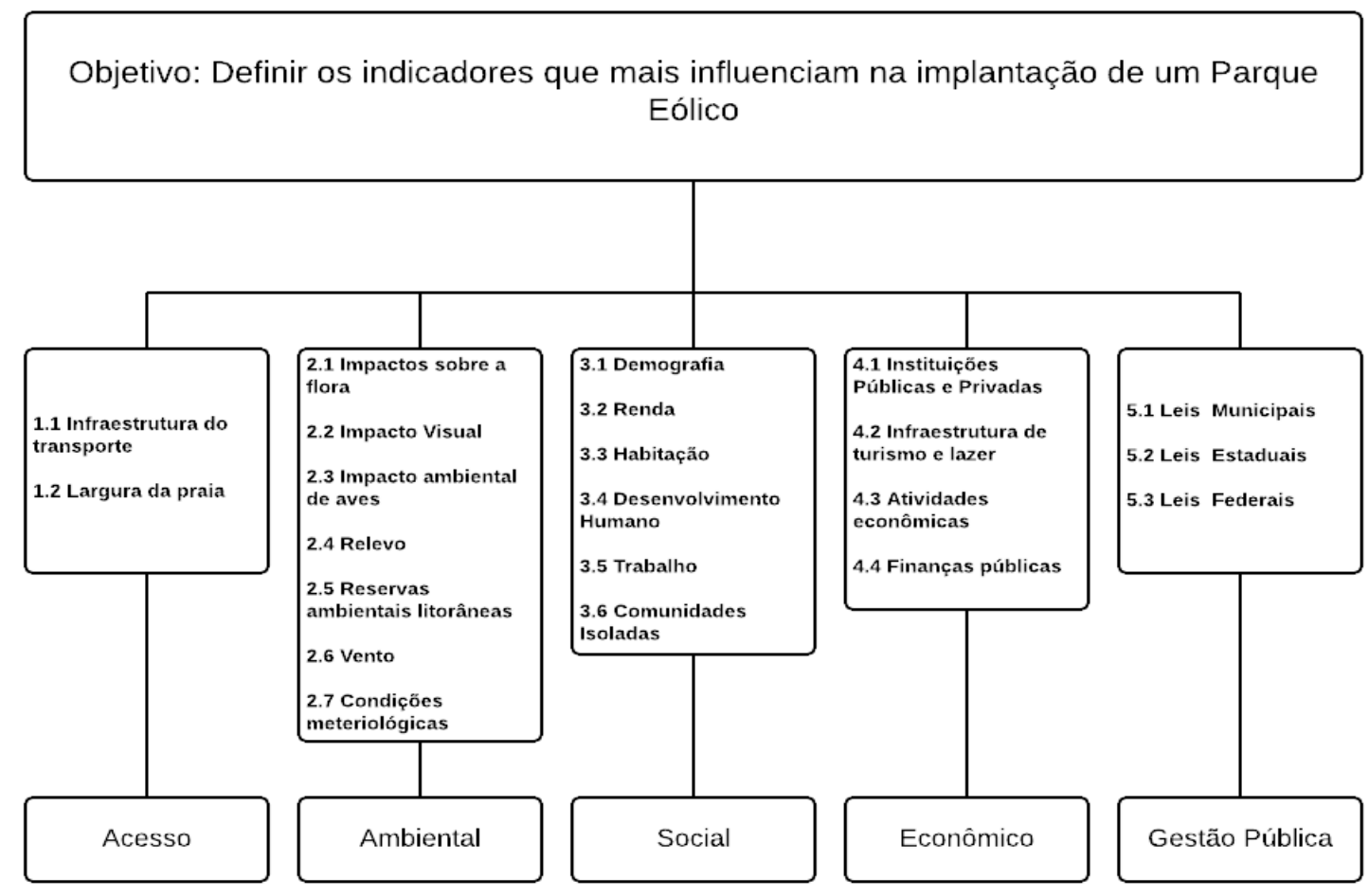

Fonte: Autores

Com a necessidade de se encontrar as prioridades em relação aos indicadores, a matriz de comparação par a par, foi enviada aos indivíduos selecionados para o teste, que responderam a matriz enviada por e-mail no prazo estipulado.

Assim, foi realizado o teste de inconsistência para cada matriz recebida separadamente, e nenhuma matriz foi descartada, pois todas apresentaram uma Razão de Consistência menor que $20 \%$. A matriz de comparação paritária enviada aos entrevistados pode ser encontrada na Figura 4, onde cada critério foi comparado par a par.

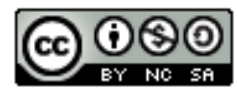


Citação (APA): Javarini, N. S., Gomes, V. A. do P., \& Freitas, R. R. de (2021). Análise da aplicação do Método AHP em indicadores de potencialidade na implantação de parques eólicos. Brazilian Journal of Production Engineering, 7(1), 17-30.

Figura 4. Matriz de julgamentos/comparação entre indicadores

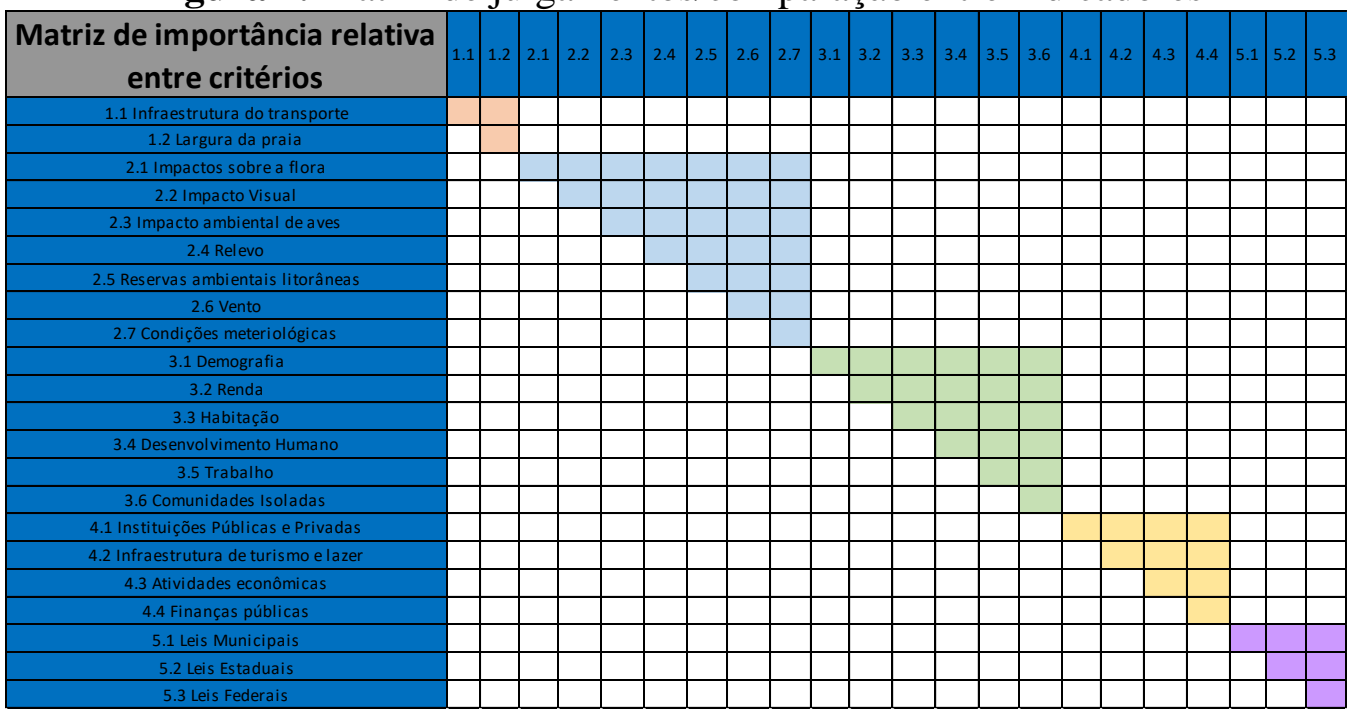

Fonte: Autores

Com relação aos critérios, segundo o julgamento dos entrevistados, o que possui maior peso é o critério 2.6 VENTO com 17,1207\%, seguido do critério 2.1 IMPACTOS SOBRE A FLORA, com o peso $8,4453 \%$. O Quadro 1 mostra a ordem prioritária dos critérios conforme a julgamento dos indivíduos que realizaram o teste:

Quadro 1. Ordem prioritária dos critérios conforme julgamento dos entrevistados no teste

\begin{tabular}{|c|c|}
\hline $17,1207 \%$ & 2.6 Vento \\
\hline $8,4453 \%$ & 2.1 Impactos sobre a flora \\
\hline $7,6053 \%$ & 2.7 Condições meteorológicas \\
\hline $5,1388 \%$ & 2.5 Reservas ambientais litorâneas \\
\hline $4,4043 \%$ & 5.1 Leis Municipais \\
\hline $4,4043 \%$ & 5.2 Leis Estaduais \\
\hline $4,4043 \%$ & 5.3 Leis Federais \\
\hline $3,9129 \%$ & 3.6 Comunidades Isoladas \\
\hline $3,3673 \%$ & 2.2 Impacto Visual \\
\hline $3,3673 \%$ & 2.3 Impacto ambiental de aves \\
\hline $2,8950 \%$ & 1.1 Infraestrutura do transporte \\
\hline $2,7037 \%$ & 2.4 Relevo \\
\hline $2,2475 \%$ & 3.2 Renda \\
\hline $2,1959 \%$ & 3.5 Trabalho \\
\hline $1,9502 \%$ & 3.3 Habitação \\
\hline $1,7983 \%$ & 3.4 Desenvolvimento Humano \\
\hline $1,7841 \%$ & 4.3 Atividades econômicas \\
\hline $1,7841 \%$ & 4.4 Finanças públicas \\
\hline $1,6972 \%$ & 4.2 Infraestrutura de turismo e lazer \\
\hline $1,6582 \%$ & 4.1 Instituições Públicas e Privadas \\
\hline $1,4844 \%$ & 3.1 Demografia \\
\hline $0,8150 \%$ & 1.2 Largura da praia \\
\hline
\end{tabular}

Fonte: Autores. 

potencialidade na implantação de parques eólicos. Brazilian Journal of Production Engineering, 7(1), 17-30.

O critério vento diz respeito a fatores como direção do vento, turbulência e velocidade do vento. Impactos sobre a flora está relacionado com o desmatamento do local onde se irá implantar a usina e até mesmo a extinção de determinadas espécies. As condições meteorológicas são compostas pelas condições do clima, chuva, sol, neve, fenômenos climáticos, temperatura etc. Reservas ambientais litorâneas são as áreas de preservação, proteção e reservadas em locais próximos ao ambiente marinho. O bloco de leis, federais, estaduais e municipais, tem relação com a legislação vigente, tanto para quesitos ambientais, como para licenças, permissões, normas, e todos os fatores previstos em lei para se implantar um parque eólico. Comunidades isoladas devem ser verificadas para que não sejam impactadas negativamente, como índios, sem terra, quilombolas, pescadores e etc.

O Impacto Visual dita sobre a paisagem e o impacto que os aerogeradores causam aos moradores próximos ao parque. Impacto ambiental de aves antigamente muito severo por não haver estudos sobre o período de migração das aves que gerava muita morte, mas que hoje em dia já é mínimo. A Infraestrutura do transporte está relacionada ao acesso, aos transportes que irão circular na usina e no acesso da usina com rodovias e redes elétricas, passando dentro de comunidades, povoados, municípios e etc.

O Relevo é dito importante para a fixação dos aerogeradoes. A sequência de Renda, Trabalho, Habitação e Desenvolvimento Humano está diretamente relacionada com a localidade e a população que nela habita, para saber o impacto que um parque eólico pode gerar socialmente. Já a sequência de Atividades econômicas, Finanças públicas, Infraestrutura de turismo e lazer e Instituições Públicas e Privadas diz respeito a condição econômica atual do local que irá receber o parque e o impacto que este pode gerar, se o investimento é viável e se o retorno será benéfico. A Demografia compõe-se de fatores como total da população, idade, densidade demográfica, empregos formais e etc. E a Largura da praia tem relação com possíveis parque eólicos que serão implantados em localidades litorâneas.

Desde modo, apresenta-se a hierarquização dos indicadores, respondendo assim ao objetivo geral, realizada por meio da soma dos critérios que compõe cada indicador, o Quadro 2 mostra a ordem prioritária das alternativas (indicadores), quando à importância destes quando se deseja implantar um parque eólico.

Quadro 2. Ordem prioritária dos indicadores teste segundo teste do método AHP

\begin{tabular}{|c|c|}
\hline Indicador & Prioridade \\
\hline Ambiental & $31,6977 \%$ \\
\hline Social & $17,2815 \%$ \\
\hline Gestão Pública & $7,9725 \%$ \\
\hline Econômico & $6,9236 \%$ \\
\hline Acesso & $6,0710 \%$ \\
\hline
\end{tabular}

Fonte: Autores

Assim, verifica-se que o indicador considerado mais importante e que deve ser considerado na implantação de um parque eólico é indicador ambiental. Ao se observar o cenário energético atual, pode-se dizer que a energia eólica é uma das grandes promessas para o futuro, visto que possui uma melhor qualidade ambiental e por sua abundância em várias partes do mundo. 

potencialidade na implantação de parques eólicos. Brazilian Journal of Production Engineering, 7(1), 17-30.

Pode-se verificar, que o critério VENTO é considerado predominante quando o intuito é discutir sobre a energia dos ventos e principalmente quando o assunto é implantação de um parque eólico. Como menciona Gebraad et al., (2016), fatores como direção do vento, velocidade do vento e turbulência devem ser levados em consideração para o processo de otimização da energia em uma usina eólica. Corroborando, Gomes \& Freitas (2019) apontam que tais fatores, se forem considerados na implantação do parque eólico podem garantir a otimização da energia desde o início de sua produção.

Quanto ao indicador ambiental se encontrar em primeiro lugar no ranking verifica-se que os critérios que compõem esse indicador se sobressaem no ranking de critérios. Tal posição justifica-se pelo fato de a energia eólica, como qualquer outra atividade industrial, também pode causar impactos no ambiente que devem ser considerados (Amponsah et al., 2014). Verifica-se que essa condição foi considerada pelos pesquisadores ao considerar o indicador ambiental como o de maior influência na implantação de um parque eólico.

A Constituição Federal (Brasil, 1988) prevê em seu art. 225 que "todos têm direito ao meio ambiente ecologicamente equilibrado, bem de uso comum do povo e essencial à sadia qualidade de vida, impondo-se ao Poder Público e à coletividade o dever de defendê-lo e preservá-lo para as presentes e futuras gerações". Com isso, o meio ambiente tornou-se direito fundamental do cidadão, cabendo tanto ao governo quanto a cada indivíduo o dever de resguardá-lo.

A defesa do meio ambiente apresenta-se também como princípio norteador e inseparável da atividade econômica na Constituição Federal. Desse modo, não são admissíveis atividades da iniciativa privada e pública que violem a proteção do meio ambiente (Brasil, 2007).

Assim, compreende-se sobre o critério que ocupa o $2^{\circ}$ lugar no ranking, a degradação do ambiente que começa ainda na etapa de implantação do parque, com a retirada da vegetação para a construção de estruturas, caminhos de acessos e ocupação física do terreno. E esse processo de remoção da vegetação tem acarretado impactos relacionados à erosão dos terrenos (Loureiro et al., 2015).

Para Azevedo, et al. (2016), o desmatamento e a erosão do solo são fatores de extrema preocupação durante a construção de um parque eólico, pois algumas atividades, como escavação, fundação e construção de estradas, podem afetar o bio-sistema local. Quando a vegetação é removida, o solo fica desprotegido contra chuvas e ventos fortes, acarretando a erosão do mesmo. Áreas com ricos recursos eólicos normalmente têm pouca biodiversidade e fracos ecossistemas. As atividades com maquinário pesado e grandes construções acabam perturbando o equilíbrio ecológico local.

O mangue é um tipo de vegetação severamente impactada quando um parque eólico é implantado em suas proximidades. De acordo com Loureiro, et al. (2015), o mangue realiza um grande papel ambiental em abrigar litorais e estuários, servindo como um terreno fértil e berçário para a vida marinha.

Wu et al., (2016) menciona em seu trabalho, que também envolve a análise multicritério, a influência das condições meteorológicas, apontando como ameaças naturais complexas (por exemplo, ciclone tropical no verão, ciclone extra tropical, anticiclone frio no inverno, blocos 

potencialidade na implantação de parques eólicos. Brazilian Journal of Production Engineering, 7(1), 17-30.

de gelo, névoa salgada) podem interferir nas condições de construção e manutenção de parques eólicos, no caso de seu estudo na China.

Mas não se pode deixar de mencionar as causas naturais simples, como tempestade, ou simplesmente a temperatura, que como explica Barros (2020):

Devido ao aquecimento solar, os ventos com maior velocidade ocorrem durante o dia. A massa de ar também difere na temperatura, interferindo assim com a velocidade do vento. Uma massa de ar quente é menos densa do que uma massa de ar frio. Portanto, uma massa de ar quente contra uma massa de ar frio causará vento. $\mathrm{O}$ oposto também influencia: Uma massa de ar frio em contato com uma massa de ar quente irá produzir vento, interferindo com a produção de energia eólica.

As reservas ambientais litorâneas, por sua vez, aparecem em $3^{\circ}$ lugar no ranking de critérios e compõe o fator ambiental que ocupa o $1^{\circ}$ lugar no ranking dos indicadores.

Não deixando de mencionar os critérios que ocupam as posições 9 e 10 do ranking, e compõem o indicador ambiental. Segundo Fadigas (2011) a poluição visual, assim como a poluição sonora, causa fortes impactos ambientais nesse setor. De acordo com Azevedo, et al. (2016), o desenvolvimento da energia eólica tem sido associado com a morte de aves que colidem com turbinas e outras estruturas que geram vento. Devido à falta de compreensão do nível de utilização aviária em áreas, algumas das primeiras instalações de turbinas de vento nos EUA causou relativamente alto risco de colisões, pois essas instalações foram localizadas em regiões onde as aves eram abundantes (Sovacool, 2013).

Para Pinto, et al. (2017), esta questão apresenta conclusões conflitantes causando certa controvérsia entre estudos atuais. Diversos trabalhos científicos argumentam que a taxa de mortalidade de aves aumentaria devido aos aerogeradores. Entretanto, isso advém principalmente da implantação dos primeiros parques eólicos, para os quais o estudo preliminar das rotas migratórias das aves não era exigido.

$\mathrm{O}$ indicador social ocupa o $2^{\circ}$ lugar no ranking, e tem-se que existe uma relação entre o consumo de energia e o desenvolvimento social de uma região (Goldemberg, \& Lucon, 2008). Para Simas \& Pacca (2013), o aproveitamento da energia eólica para gerar eletricidade é um importante fator de desenvolvimento social, principalmente se utilizado para atender a comunidades isoladas e erradicar a miséria em regiões de maior vulnerabilidade social, permitindo a universalização do uso da energia a custos menores, geração de empregos, além de consequente redução do êxodo rural. "No entanto, decisões sobre a localização de parques eólicos devem ser tomadas levando em consideração também os usos da terra na região de interesse" (Pinto et al., 2017).

E de acordo com Barbosa Filho \& Azevedo (2014), todo tipo de planejamento relacionado à implantações de parques eólico deve ser alinhado com as perspectivas e políticas de expansão da energia eólica no país e com a definição de um zoneamento ecológico-econômico para energia eólica e demais leis pertinentes, justificando o $3^{\circ}$ lugar no ranking das questões de gestão pública.

Questões como aspectos econômicos e de acesso a um parque eólico, pode-se verificar que não devem ser desconsiderados, porém quando comparados aos outros indicadores, estes 

potencialidade na implantação de parques eólicos. Brazilian Journal of Production Engineering, 7(1), 17-30.

apresentam menor grau de importância de acordo com os pesquisadores que responderam a matriz deste estudo.

Wu et al. (2016) traz como composição de critérios econômicos, o investimento total, o período total do retorno do projeto, a proporção esperada de B/C, os custos de operação e manutenção e os subsídios financeiros locais. Que são item de extrema importância ao se avaliar a implantação de parque eólio. Tegou et al., (2010), por sua vez, apresenta o valor da terra como um critério econômico, e outros dois critérios que tem total relação com o critério acesso, que são distancia da rede elétrica e distancia da rede rodoviária. Dessa forma, justifica-se o porquê desses aspectos serem considerados na implantação.

\section{CONCluSÃo}

Conclui-se que o objetivo deste estudo foi alcançado, visto que foi possível discutir sobre os indicadores que influenciam na instalação de um parque eólico, por meio de comparações paritárias, de acordo com o método AHP. Sendo que este estudo pode servir de base para tomadores de decisão, no que se diz respeito a instalação de parques eólicos ou outras infraestruturas que em que se faça necessário a análise de critérios para uma escolha ótima.

A partir da hierarquização realizada, foi possível verificar que o indicador que ocupou o primeiro lugar no ranking de tomada de decisão, foi o ambiental, este por sua vez teve maiores pesos nos critérios que o compõe. Em especial o critério VENTO, que se destacou na opinião dos pesquisadores, sendo aquele que exerce uma maior influência quando se pensa em implantação de parque eólico.

Percebe-se que os percentuais encontrados foram consideravelmente distintos para os indicadores que ocuparam as primeiras 3 posições no ranking, e manteve a mesma discrepância no ranking dos critérios. Mas destacando o vento, como fundamental nesta tomada de decisão.

Verificou-se como os critérios pertencentes ao indicador ambiental possuem a preferência na opinião dos pesquisadores, visto que o ambiente acaba sendo a maior preocupação em questões de energia eólica.

As condições sociais por sua vez, merecem destaque em sua totalidade, não deixando de se perceber a importância do grupo de leis que regem as condições de implantação de parques eólicos. Os indicadores econômico e acesso apresentaram percentuais muito próximos neste estudo, logo, possuem sua parcela de importância, porém não se torna prioridade quando comparado com os demais indicadores.

Com o exposto, verifica-se o auxílio do Método AHP e sua contribuição na tomada de decisão, levando em consideração a opinião de pesquisadores que realizaram o teste. É possível ainda, confirmar que o teste foi compreendido pelos indivíduos que o respondeu, sendo que para futuras aplicações este método de envio de questionários pode ser aplicado. Para trabalhos futuros, sugere-se a busca por possíveis localidades para a implantação de parques eólicos utilizando o Método AHP. 

potencialidade na implantação de parques eólicos. Brazilian Journal of Production Engineering, 7(1), 17-30.

\section{REFERÊNCIAS}

Abeeólica - Associação Brasileira de Energia Eólica. (2020). Eólica: energia para um futuro inovador.

Amponsah, N., Troldborg, M., Kington, B., Aalders, I., \& Hough, R. L. (2014). Greenhouse gas emissions from renewable energy sources: A review of life cycle considerations. Renewable and Sustainable Energy Reviews, 39, 461-475.

Azevedo, J. P. M., Nascimento, R. S., \& Schram, I. B. (2016). Energia eólica e impactos ambientais: um estudo de revisão. XX Encontro Latino Americano de Iniciação Científica, XVI Encontro Latino Americano de Pós-Graduação e VI Encontro de Iniciação à Docência Universidade do Vale do Paraíba.

Barbosa Filho, W. P., \& Azevedo, A. C. S. (2014). O uso da análise hierárquica como auxílio na tomada de decisão de políticas públicas em energia eólica considerando aspectos de sustentabilidade. In: Congresso De Energia Solar, 5., 2014, Recife. Trabalhos... Recife: ABENS.

Barros, B. Z. (2020). Conheça os fatores que influenciam na produção de energia eólica. Engenharia 360.

Bechert, D., Santos, K. C., Neumann, P. N., \& Edler, M. A. R. (2015). Eletricidade e meio ambiente: uma nova forma de pensar. REVINT, Cruz Alta, 3(1), 245-257.

Berzins, L. J. (2009). Avaliação de Desempenho pelo AHP, através do superdecisions; Caso Inmetro. Dissertação (Mestrado Profissionalizante) Programa de Pós-Graduação em Administração das Faculdades Ibmec.

Brasil. (1988). Constituição da República Federativa do Brasil. Brasília, DF: Senado Federal: Centro Gráfico.

Brasil. (2007). Tribunal de Contas da União. Cartilha de licenciamento ambiental. 2. ed. Brasília:TCU.

Britol, E. B. S., \& Magalhães, L. L. (2017). Marketing de relacionamento e sua influência no processo de captação e retenção de clientes na Tallis Joias e Óticas. Revista de Administração da UNI7, 1, 151-183.

Chaer, G., Diniz, R. R. P., \& Ribeiro, E. A. (2011). A técnica do questionário na pesquisa educacional. Revista Evidência, 7(7), 251-266.

Colin, E. C. (2007). Pesquisa Operacional - 170 Aplicações em estratégia, finanças, logística, produção, marketing e vendas. São Paulo: Atlas.

Fadigas, E. A. F. A. (2011). Energia eólica - Série sustentabilidade. Rio Grande do Sul: Editora Antus.

Gazzaneo, B. P. B. (2008). Pré-seleção de ações para a Construção de Carteiras eficientes. Dissertação (Mestrado Profissionalizante em Administração), Faculdade IBMEC.

Gebraad, P. M. O., Teeuwisse, F. W., Van Wingerden, J. W., Fleming, P. A., Ruben, S. D., Marden, J. R., \& Pao, L. Y. (2016). Wind plant power optimization through yaw control using a parametric model for wake effects-a CFD simulation study. Wind Energy, 19(1), 95-114.

Goldemberg, J., \& Lucon, O. (2008). Energia, meio ambiente e desenvolvimento. 3. ed. São Paulo: EDUSP. 
Citação (APA): Javarini, N. S., Gomes, V. A. do P., \& Freitas, R. R. de (2021). Análise da aplicação do Método AHP em indicadores de potencialidade na implantação de parques eólicos. Brazilian Journal of Production Engineering, 7(1), 17-30.

Gomes, L. E. B., \& Henkes, J. A. (2015). Análise da energia eólica no cenário elétrico: aspectos gerais e indicadores de viabilidade econômica. R. Gest. Sust. Ambient., Florianópolis, 3(2), 463482.

Gomes, V. A. P., \& Freitas, R. R. (2019). Wind Farm Implementation Factors: A Bibliometric Analysis. International Journal of Advanced Engineering Research and Science, 6(8).

Gomes, V. A. P., Julio, T. S., \& Freitas, R. R. (2016). IPSPA: Construção de um Índice de Potencialidade Socioeconômico, Produtivo e Ambiental Pesqueiro utilizando o Método AHP. Brazilian Journal of Production Engineering, 2(1), 72-83.

Hinrichs, A. R., \& Kleinbach, M. (2003). Energia e meio ambiente. Trad. De Flávio Maron Vichi e Leonardo Freire Mello. 3. ed. São Paulo: Pioneira Thomson Learning.

Loureiro, C. V., Gorayeb, A., \& Brannstrom, C. (2015). Implantação deenergia eólica e estimativa das perdasambientais em um setor do litoral oeste do Ceará, Brasil1․ Geosaberes, 6(especial (1)), $24-38$.

MME - Ministério de Minas e Energia. (2007). Plano Nacional de Eficiência Energética: premissas e diretrizes básicas.

MURIUCI, S., FERRI, M. S., \& FELICETTI, V. L. (2012). Uma sombra na Educação Brasileira: do ensino regular ao paralelo. 2012, [S.1.]: IX ANPED SUL - Seminário de Pesquisa em Educação da Região Sul,1-20.

Nascimento, T. C., Mendonça, A. T. B. B., \& Cunha, S. K. (2012). Inovação e sustentabilidade na produção de energia: o caso do sistema setorial de energia eólica no Brasil. Cad. EBAPE.BR, 10(3), 630-651, Sept.

Pereira Neto, A. (2013). A tutela jurídica da energia eólica no Brasil. 2013. 132 f. Dissertação (Mestrado em Direito) - Escola Superior Dom Helder Câmara, Belo Horizonte.

Pinto, A. C., \& Santo Neto, P. J. S. (2012). Uma Revisão do Estado da Arte sobre a Aplicação de Aerogeradores de Pequeno Porte no Contexto das Redes Inteligentes. Revista Ciências Exatas e Naturais, 14(1), Jan/Jun.

Pinto, L. I. C., Martins, F. R., \& Pereira, E. B. (2017). O mercado brasileiro da energia eólica, impactos sociais e ambientais. Revista Ambiente \& Água, 12(6), 1082-1100.

Ruy, M., \& De Paula, V. M. F. (2012). Ferramenta Computacional de Apoio ao Ensino do Método de Análise Hierárquica em Cursos de Graduação em Engenharia de Produção. In: XXXII Encontro Nacional de Engenharia de Produção, 2012, Bento Gonçalves - RS. Anais... Bento Gonçalves: ABEPRO.

Saaty, T. L. \& Vargas, L. G. (1979). Estimating technological coefficients by the analytic hierarchy process. Socio-Economic Planning Sciences, 13(6), 333-336.

Saaty, T. L. (1980). The Analytic Hierarchy Process and Health Care Problems. New York: McGraw-Hill.

Saaty, T. L. (1988). The analytic hierarchy process. New York, NY: Pergamon Press.

Saaty, T. L. (1990). How to make a decision: The analytic hierarchy process. European Journal of Operational Research, Amsterdam, 48, 9-26.

Saaty, T. L. (1991). Método de Análise Hierárquica. McGraw-Hill, Makron Books, São Paulo, SP, Brasil. 367p. 


$$
\text { - } 30 \text { - }
$$

Citação (APA): Javarini, N. S., Gomes, V. A. do P., \& Freitas, R. R. de (2021). Análise da aplicação do Método AHP em indicadores de potencialidade na implantação de parques eólicos. Brazilian Journal of Production Engineering, 7(1), 17-30.

Saaty, T. L. (2000). Decision making for leaders. Pittsburg, USA: WS. Publications.

Saaty, T. L. (2001). Decision Making with Dependence and Feedback: the Analytic Network Process, 2nd edition, Pittsburgh (USA): RWS.

Silveira, L. D. M. (2017). A produção de energia eólica e seu potencial para desenvolvimento sustentável. XXXVII Encontro Nacional de Engenheria de Produção, Joinville.

Simas, M., \& Pacca, S. (2013). Energia eólica, geração de empregos e desenvolvimento sustentável. Estudos Avançados, 27(77), 99-115.

Sovacool, B. K. (2013). The avian benefits of wind energy: A 2009 update. Renewable Energy, 49, 19-24.

Tegou, L. I., Polatidis, H., \& Haralambopoulos, D. A. (2010). Environmental management framework for wind farm siting: Methodology and case study. Journal Of Environmental Management, 91(11), 2134-2147.

Wu, Y. N., Zhang, J. Y., Yuan, J. P., Geng, S., \& Zhang, H. B. (2016). Study of decision framework of offshore wind power station site selection based on ELECTRE-III under intuitionistic fuzzy environment: A case of China. Energy Conversion and Management, 113, 66-81. 